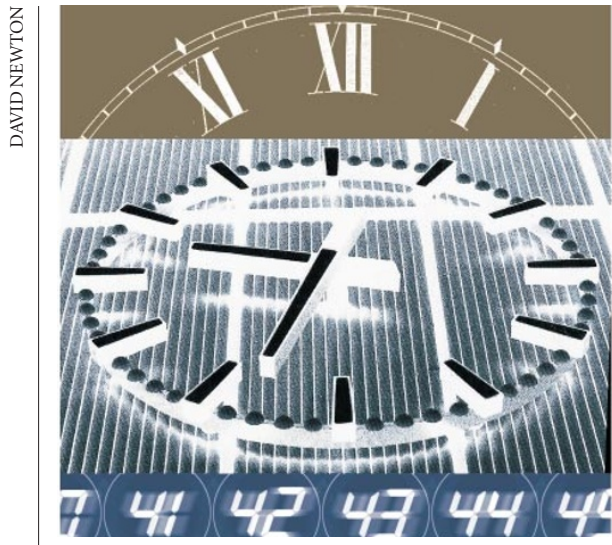

years ago that there are so many journals sprouting up that soon there will be a Journal of Shear Stress comes to mind), while now I mostly receive announcements that our library is cancelling journals. Yet new journals do continue to appear - and we wonder in each case if the world would have been better off with the trees.

There is no doubt that some new journals appear because a particular field is currently 'hot', only for the journals to disappear after the field cools. But in other cases, there is a community of scholars working on similar problems but in different contexts, and doing their research in different departments and fields. The logical next step is to establish a journal to connect these scholars and to provide a forum for their output. How do we then decide if the tree/journal balance is a favourable one?

I believe that the decision depends on the generality of the subject, its long-term importance to science and technology in general, and how large the potential community is. In the case of the potential audience for Mechanics of Time-Dependent Materials, there is a large and disparate community working in the field, but they are separated by material systems, discipline and department. As a result, this critical materials problem tends to be marginalized in the typical journal. Many of us study the microstructural details that lead to a time-dependence in a given material behaviour. But we tend not to study the details of the time-dependence itself, and we are even less likely to model it carefully so that it can be described in analytical detail.

The goal of this journal is to provide a forum for researchers whose focus is on the time-dependence itself and to inject more science into issues of durability and ageing than has been the case in the past.

The journal has clearly made a slow start. Five issues have appeared since its inception in 1997, with the sixth due out soon, but the frequency of publication is increasing. The articles published are true to the journal's goals, focusing on time-dependence itself in materials ranging from foams to epoxies to polycrystalline metals to composites. Those for whom the details of time-dependent material behaviour is essential should read and publish in this journal.

David P. Pope is in the Department of Materials Science and Engineering, University of Pennsylvania, LRSM Building, 3231 Walnut Street, Philadelphia, PA 19104, USA.

\section{. Working together for the Earth}

\section{Environmental Science \& Policy}

Editor-in-chief Joe Wisniewski

Elsevier. 6/yr. \$477, DFl 940

\section{David G. Victor}

The objective of this journal is to "build bridges among and between scientists, policy makers and decision-makers in industry". In practice, as this journal shows, that worthy goal is difficult to meet.

Of the journal's strongest articles, most are written for specialists and build few bridges with other disciplines or decisionmakers. Policy implications are left latent or are stated so broadly as to be of little use for real decision-making. Such studies belong in traditional disciplinary journals. Glaring in its absence from the four numbers provided for this review was the discipline of economics, which is a vital guide as policy makers struggle to allocate scarce resources. Also scant is attention to the implications of uncertainty for policy choices.

About half the articles reviewed are brief surveys or comments on existing research. They lack the depth needed to push the frontier of policy research or to synthesize research across disciplines to create new insights and bridges. Perhaps such articles would appeal to readers who have a broad interest in policy and environmental science, but few general readers are likely to glance at this journal-not least because the publisher has put the cost of subscriptions in the stratosphere.

However, a few gems shine. Among them is the study of carbon that is accumulating in the Canadian forest products sector (FPS) such as in wooden buildings, landfills, pulp and paper (vol. 2, no. 1, 25-41). Most forest carbon is in the forests themselves, but the authors show that FPS carbon is a large part of the net flux of Canadian forest carbon and a growing fraction of the FPS flux crosses political borders because forest products are increasingly traded overseas.

Such studies underscore how tricky it will be to create an accurate and comprehensive system for tracking carbon. This year, Environmental Science \& Policy devoted a whole issue to this problem. The Kyoto Protocol, which limits fluxes of carbon dioxide and other gases that cause global warming, makes the issue urgent. The papers identify the technical hurdles and show that countries will be unable to assure their compliance with the protocol until an accounting system is agreed.

This journal has not yet found its voice, but its goals are important and there are hints as to how they can be met.

David G. Victor is at the Council on Foreign

Relations, 58 East 68th Street, New York, NY10021, USA.

\section{Modern questions in a traditional form}

\section{Studies in History and Philosophy of Biological and Biomedical Sciences \\ Editor N. Jardine \\ Pergamon. 4/yr. \$197, 176.52 euros \\ (institutional); $\$ 45,40.39$ euros (personal)}

\section{W. F. Bynum}

Few disciplines seem to have such a high ratio of journals to practitioners as the history and philosophy of science, medicine and technology. The history and the philosophy of science have tended to drift apart over the past few decades, because of increasing specialization and the discovery of the subject by scholars originally trained in history or philosophy. For some, the social history of medicine or science is pretty much all there is to it. Traditional philosophers of science are bemused by the emphasis on the social, as opposed to the cognitive, content of this historiography, and feel beleaguered by the burgeoning field of bioethics.

Studies in History and Philosophy of Biological and Biomedical Sciences, the product of a 1998 fission of an existing journal (Studies in History and Philosophy of Science), combines both traditional and cutting-edge features. It is traditional in offering space for both philosophers and historians; tradition$\mathrm{al}$, too, in that its philosophical balance is within the realism with which most scientists identify (discovery rather than social construction is the name of the game). Thus, Nils Roll-Hansen has some sharp criticisms of Bruno Latour's anthropological account of laboratory life, and Martha Keyes' analysis of the relationship between prions and molecular biology's central dogma takes the science seriously.

At the same time, the articles in the first four issues were written by professionals within the broadly defined field of 'science studies'. They are aware of the variety of approaches that have been used to examine the creation of scientific knowledge. They articulate the wider issues of social responsibility and power that permeate the modern scientific enterprise. Almost all of the articles 
deal with nineteenth- or twentieth-century science, and most conform to the wish, expressed in the inaugural editorial, of providing information and interpretation that should interest practising scientists. Topics include interferon, Caenorhabditis elegans, gene mapping, Helicobacter pylori and the images of Barbara McClintock.

Consequently, this new journal can be welcomed as an important forum for contemporary debate. Within its first two volumes it has grown from two to four issues a year, in itself perhaps a reflection that the field is still growing.

W. F. Bynum is at the Wellcome Institute for the History of Medicine, 183 Euston Road, London NW1 2BE, UK.

\section{New shoots to replace the old?}

\section{Current Opinion in Plant Biology}

Editors Keith Roberts and Chris Somerville Current Biology Publications. 6/yr. Print

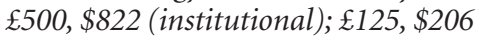

(personal). Online $\$ 227$ (personal only).

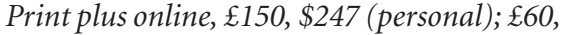
$\$ 90$ (student)

\section{Ortrun Mittelsten Scheid}

Current Opinion is the family name of quite a prolific clan. Last year, the parents at Current Biology Publications announced the birth of a new child, Plant Biology. Its bright green colour distinguishes it from its brothers and sisters on the shelf, but once opened it cannot conceal extensive family likenesses.

The concept of a bimonthly collection of invited, well-prepared reviews has proven very successful in other rapidly developing fields such as biotechnology, genetics and development, cell biology, immunology, neurobiology and others. But unavoidable overlap with other family members and with other review journals (related by the marriage between CBP and Elsevier) suggests a birth-control plan would now be in order.

The issues are grouped around growth and development (February), genome studies and molecular genetics (April), physiology and metabolism (June), plant microbe interaction (August), cell signalling and gene regulation (October), and cell biology (December). Each issue starts with Paper Alert, a personal but widely agreeable selection of important primary publications in all six fields, and Web Alert suggesting useful Internet sites. The editorial overview that follows usually comes closest to the family name and the intention expressed in the first volume - "to provide informed opinions about the burden of evidence and possible directions for new discoveries".

The reviews I read had much less of the opinion component. However, they were excellent summaries with informative introductions and a good compilation of basic as well as the most recent data, supported by suitable figures when necessary, and were followed by an extensive and ranked reference list. So far little use has been made of the ability to offer supplementary material such as video documentation via the publisher's home page, but this may change in the future. The concept of covering the same areas in the same month each year will render the journal an attractive source of information, also for readers who are not fond of systematic or computerbased literature search.

The price is high, but not unreasonable. Some institutions will not be able to add it to the budget without cancelling other subscriptions. But there is a good chance that this new member of the family will develop well, protected by its caring parents, the publishers, and its prominent godfathers

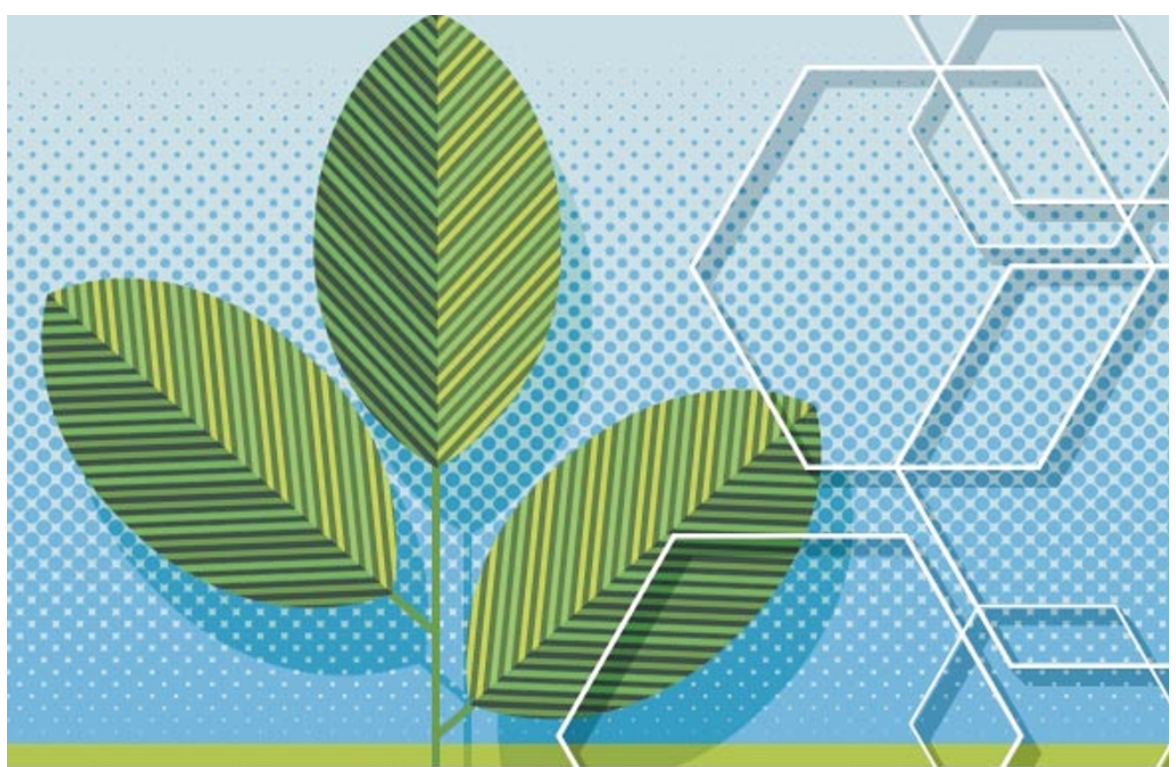

Roberts and Somerville. It is worth investing in its future, and going for a change of generation on the library shelves.

Ortrun Mittelsten Scheid is at the

Friedrich Miescher Institute, P.O. Box 2543,

CH 4002 Basel, Switzerland.

\section{Grains of wisdom unite two disciplines}

\section{Granular Matter}

Editors-in-chief R. P. Behringer and

H. J. Herrmann

Springer. 4/yr. \$332, DM498

\section{Dov Levine}

Granular materials such as sand are agglomerations of many macroscopic, hard, heavy particles, or grains. The grains don't deform appreciably, there are no randomizing effects of temperature and they dissipate energy in collisions and through friction.

Although granular materials may appear simple, the study of their physical properties is difficult: they are quintessential manybody systems, and knowing the interaction between two grains does not imply understanding of the system as a whole. They exhibit a wealth of fascinating behaviour, including novel pattern formation and interesting flow characteristics. Because of their strong dissipation, granular materials jam into static states whose properties are not amenable to standard statistical mechanics. The way force propagates in these states is different from any other system.

Engineers have long studied granular materials because of their importance in industry, while physicists have become interested more recently. The questions asked by the two communities are not always different, but the background assumed, the experimental tools used and the notation employed certainly make the papers look different. And, as is perhaps common in active interdisciplinary fields, there is a certain tension between the camps and the search for common ground is not always smooth.

Granular Matter was created to help find that common ground. Since there are so many journals in physics and engineering already, the editors' foremost aim is unification. This aims to be the journal of choice for the entire community, so that researchers of all backgrounds will be made aware of different approaches. This is a commendable idea for this exciting field. The first issues have had a nice collection of papers with a varied mix of authors, so Granular Matter is off to a good start. It is to be hoped that physics and engineering libraries alike will choose to add it to their shelves.

Dov Levine is in the Department of Physics,

Technion, 32000 Haifa, Israel. 